\title{
Rapid separation of Capsicum annuum $L$. leaf extract using automated HPLC/SPE/HPLC coupling system (Sepbox system) and identification of a-glucosidase inhibitory active substances
}

\author{
Min-Seon Kim ${ }^{1}$ Jong Beom Jin ${ }^{1} \cdot$ Jung Hwan Lee ${ }^{1} \cdot$ Hye Suck An ${ }^{2}$. \\ Cheol-Ho Pan ${ }^{1}$ (D) · Jin-Soo Park ${ }^{1}$ (D)

\section{자동화 HPLC/SPE/HPLC 시스템(Sepbox system)을 활용한 고추 잎 (leaf of Capsicum annuum L.) 추출물 분리 및 a-glucosidase 억제 활성 물질 탐색}

김민선 ${ }^{1} \cdot$ 진종범 $^{1} \cdot$ 이정 환 ${ }^{1} \cdot$ 안혜숙 $^{2} \cdot$ 판철호 $^{1} \cdot$ 박진수 $^{1}$

\begin{abstract}
Phytochemicals include plant-derived natural products that promote and improve the human metabolism and physiological activity, and there is a lot of research to find the value of the molecules is in progress. Likewise, we obtained 288 fractions of Capsicum annuum L. extract in less than $20 \mathrm{~h}$ using HPLC/SPE/ HPLC coupling experiment through Sepbox system, an effective separation system to search for active substances in natural resources and ensure efficacy and reliability. Therefore, this experiment allowed rapid identification of biologically active molecules from the extract compared to traditional separation processes. Of the above fractions, eight fractions showed the $\alpha$ glucosidase inhibitory (AGI) activity and subsequent LC-MS analysis revealed one of the active molecules as luteolin 7-O-
\end{abstract}

Jin-Soo Park $(\bowtie)$

E-mail:jinsoopark@kist.re.kr

${ }^{1}$ Natural Product Informatics Research Center, Korea Institute of Science and Technology, Gangneung 25451, Republic of Korea

${ }^{2}$ Marine Biology Research Division, National Marine Biodiversity Institute of Korea, 75, Jangsan-ro 101-gil, Janghang-eup, Seocheon-gun, Chungcheongnam-do 33662, Republic of Korea

This is an Open Access article distributed under the terms of the Creative Commons Attribution Non-Commercial License (http://creativecommons. org/licenses/by-nc/3.0/) which permits unrestricted non-commercial use, distribution, and reproduction in any medium, provided the original work is properly cited. glucoside. In addition, we proved the increase in AGI activity according to deglycosylation of flavonoid glycoside. Therefore, this study suggests that the Sepbox system can quickly separate and identify active components from plant extract, and is an effective technique for finding new active substances.

Keywords $\alpha$-glucosidase inhibitory activity $\cdot$ Capsicum annuum L. · Deglycosylation $\cdot$ Sepbox system

서 론

약용 식물은 높은 약리 활성과 약한 독성을 가지는 특성으로 인해 오래전부터 치료를 위한 목적으로 사용되어 왔고[1], Phytochemicals은 인간의 신진대사와 생리활성을 촉진하고 개선 하여 이에 대한 많은 연구결과가 보고되어 있다[2]. 치료제 개 발을 위한 선도물질로서 Phytochemical의 발견은 일반적으로 bioassay-guided fractionation의 수행으로 이루어지며[3], 용매추 출, 추출물 분획, 분획별 활성평가, 활성분획의 화합물 분리, 분 리한 화합물의 활성 점검 및 구조 동정으로 이루어진다[4,5].

그러나, 위와 같은 분리 방법은 긴 시간을 필요로 하며 용매 의 소모가 많고, 흡착된 샘플을 회수하기 어려운 경우가 빈번 하게 일어난다[6]. 이로 인해, 활성 화합물을 분리하는데 실패 하거나, 활성을 상실하는 것은 매우 흔하게 일어나며, 분리과정 
중 활성물질 변성, 미량성분의 비효율적 분리, 화합물간의 시너 지 효과로 의한 활성 등이 원인으로 파악된다[7,8]. 따라서, 생 물자원의 활성물질을 탐색하고 효능과 신뢰성을 보장하기 위한 더 나은 전략적 정제 기술이 요구되어 지고있다.

Sepbox system은 high-performance liquid chromatography (HPLC)와 solid-phase extraction (SPE)의 자동화 조합을 기반 으로 생물자원에서 화합물을 분리하는 기술로[9], 빠른 화합물 분리와 높은 회수율 등의 장점을 가지고 있다 [10]. 또한, 미량 으로 존재하여 일반적으로 검출하기 힘든 화합물들을 빠르고 효 과적으로 검출 분리가 가능하여 전통적인 분리방법의 bioassayguided fractionation의 단점을 보완할 수 있다.

고추(Capsicum annuum L.)는 가지과에 속하는 식물로 주 생 산지는 남아메리카 열대 지역이나, 한국을 포함한 전세계에서 재배되고 있고[11], 여러해살이나무이지만 우리나라에서는 한해 살이풀처럼 재배되고있다[12-14]. 고추는 페놀 화합물, carotenoid, ascorbic acid, tocopherol 및 capsaicin과 같은 다양한 생리 활 성 화합물을 포함하고 이러한 화합물은 주로 항산화제 역할을 하여 암, 심혈관 질환 및 신경 퇴행성 질환과 같은 일부 산화 스트레스 질병의 발생을 예방하고, 다양한 건강상의 이점을 제 공한다[15-18].

당뇨병은 고혈당을 특징으로 하는 대사성 질환으로, 비만과 관련되어 현대사회의 심각한 질병으로 인식되고 있다[19,20]. 당 뇨와 관련하여 $\alpha$-glucosidase는 소화효소로서 탄수화물을 단당 류로 가수분해하는 작용을 한다. 따라서, $\alpha$-glucosidase inhibitor 는 탄수화물 가수분해 저해를 통해 혈당 상승을 조절하고 당뇨 합병증의 예방에 사용되고 있어 관련 연구는 지속적으로 이루 어지고 있다[21,22].

따라서, 본 연구에서는 Sepbox system을 이용하여 효과적으 로 추출물을 분리하고, bioassay-guide 법을 이용하여 빠르고 신 속하게 $\alpha$-glucosidase inhibitor 활성을 가지는 물질을 탐색하고 자 연구를 수행하였다.

\section{재료 및 방법}

\section{시료 및 추출}

본 연구에 사용된 고추 잎은 (주)고추와 육종에서 고추잎분말로 수령하였으며, $70 \%$ ethanol과 혼합 후, 1 시간 동안 sonication하 고 24시간 냉침하였다. 이후, paper filter로 여과하고 감압농축
하여 조추출물 $\mathrm{CP} 1$ 을 조제하여 실험에 사용하였다.

\section{Sepbox chromatography separation}

Sepbox 시스템은 HPLC와 SPE의 장점을 결합하고 HPLC/SPE/ HPLC 설정과 결합되어 2차원 분리가 가능한 기술이다. 본 연 구에서는 Sepbox 2D-250 시스템(Sepiatec GmbH, Berlin, Germany) 을 이용하여 고추 잎 추출물 $(\mathrm{CP} 1)$ 을 분리하였으며, sepbox 분 획과정은 다음과 같다. C4 reverse-phase resin (Sepiatec) $0.8 \mathrm{~g}$ 에 추출물 $0.25 \mathrm{~g}$ 을 흡착시킨 후, $\mathrm{C} 4$ reverse-phase HPLC column을 사용하여 12 개의 분획으로 분리하였으며, 이후 분획 물은 12 개의 $\mathrm{SPE}$ trap column으로 이동하게 되고, 각 $\mathrm{SPE}$ column의 분획물은 C18 RP HPLC 컬럼에서 최종적으로 분리 된다. 이들은 UV $(254 \mathrm{~nm})$ 및 $\mathrm{ELSD}$ 검출기를 통해 분석되었 으며, 총 288개의 소분획(1 12T-1 24로 명명)을 확보하였다. 분 리 조건은 Table 1, 2에 나타내었다.

\section{HPLC 및 LC-MS, UHPLC-HRMS analysis}

HPLC 분석을 위해 Agilent $1200 \mathrm{HPLC} / \mathrm{MS}$ (Agilent Co., Santa Clara, CA, USA) 장비를 사용하였으며, column은 Phenomenex $5 \mu \mathrm{m} \mathrm{C} 18,150 \times 4.6 \mathrm{~mm}$ 을 사용하였다. 분석조건은 $0.05 \% \mathrm{FA}$ (formic acid)를 함유한 water와 acetonitrile을 사용하여, 0.7 $\mathrm{mL} / \mathrm{min}$ 의 유속, $10 \mu \mathrm{L}$ 의 시료를 주입하여 gradient 조건 $(\mathrm{ACN}$ $10-100 \%$ )으로 30 분 동안 분석하였다. UHPLC-HRMS 분석을 위해 Vanquish Flex UHPLC/Q-exactive Orbitrap MS (Thermo Scientific, Waltham, MA, USA)를 사용하였고 $0.3 \mathrm{~mL} / \mathrm{min}$ 유 속으로 10 분간 $\mathrm{HPLC}$ 와 동일한 용매조건으로 분석하였다.

\section{a-Glucosidase inhibitory activity assay}

$\alpha$-Glucosidase는 장의 말단에 존재하는 당분해효소로서 이들의 저해제는 탄수화물의 포도당으로 소화를 지연시킴으로써, 혈당 치를 감소시키는 역할을 한다. $\alpha$-Glucosidase inhibitory activity 의 측정방법은 다음과 같다. 샘플 $2 \mu \mathrm{L}$ 에 $125 \mathrm{nM} \alpha$-glucosidase 효소액(Sigma-Aldrich, St. Louis, MA, USA) $40 \mu \mathrm{L}, 200 \mathrm{mM}$ potassium phosphate buffer (pH 7.0) $38 \mu \mathrm{L}$ 를 혼합하여 $37{ }^{\circ} \mathrm{C}$ 에서 10 분간 배양한 후 $2.5 \mathrm{mM}$ p-nitrophenyl $\alpha \mathrm{D}$-glucopyranoside (Sigma-Aldrich) $20 \mu \mathrm{L}$ 를 첨가하여 $37^{\circ} \mathrm{C}$ 에서 20 분 간 반응시켰 다. 이후, $0.2 \mathrm{M}$ sodium carbonate (Sigma-Aldrich) $75 \mu \mathrm{L}$ 로 반응을 정지시켜 $405 \mathrm{~nm}$ 에서 흡광도를 측정하였다. 저해활성은 다음과 같이 계산하였다.

Table $11^{\text {st }}$ Separation condition of Sepbox system

\begin{tabular}{cccc}
\hline \hline $1^{\text {st }}$ Separation & Elution time $(\mathrm{min})$ & MeOH/water (\%) & Flow rate $(\mathrm{mL} / \mathrm{min})$ \\
\hline & $0-4$ & $0 / 100$ & 4 \\
& $4-7$ & $0 / 100-2 / 98$ & $4-5$ \\
C4 RP HPLC column & $7-10$ & $2 / 98$ & 5 \\
20×200 mm & $10-14$ & $2 / 98-15 / 85$ & $5-6.5$ \\
& $14-44$ & $15 / 85-90 / 10$ & 6.5 \\
& $44-50$ & $90 / 10-100 / 0$ & $6.5-5$ \\
& $50-65$ & $100 / 0$ & 5
\end{tabular}

*Water pump flow (mL/min): 0-16 min: 0, 16-18 min: 9, 18-22 min: 9, $22-26$ min: 9-8, $26-30$ min: 8-7, 30-40 min: 7-6, 40-43 min: 6-5, 43-55 min: 53, 55-60 min: 3-0 
Table $22^{\text {nd }}$ Separation condition of Sepbox system

\begin{tabular}{|c|c|c|c|c|}
\hline & & Elution time & "Acetonitrile/water & Flow rate $(\mathrm{mL} / \mathrm{min})$ \\
\hline \multirow{4}{*}{ Trap 1} & \multirow{4}{*}{$\begin{array}{c}\text { SPE1 } \\
\text { Column } 2.4^{\mathrm{a}}\end{array}$} & $0-4 \min$ & $5 / 95$ & \multirow{4}{*}{3} \\
\hline & & $4-48 \min$ & $5 / 95-15 / 85$ & \\
\hline & & $48-53 \mathrm{~min}$ & $15 / 85-45 / 55$ & \\
\hline & & $53-65 \mathrm{~min}$ & $45 / 55$ & \\
\hline \multirow{4}{*}{ Trap 2} & \multirow{4}{*}{$\begin{array}{c}\text { SPE2 } \\
\text { Column } 2.4\end{array}$} & $0-4 \min$ & 9/91 & \multirow{4}{*}{3} \\
\hline & & 4-48 $\min$ & $9 / 91-24 / 76$ & \\
\hline & & $48-53 \mathrm{~min}$ & $24 / 76-48 / 52$ & \\
\hline & & $53-65 \mathrm{~min}$ & $48 / 52$ & \\
\hline \multirow{3}{*}{ Trap 3} & \multirow{3}{*}{$\begin{array}{c}\text { SPE3 } \\
\text { Column } 2.4\end{array}$} & $0-48 \min$ & $13 / 87-33 / 67$ & \multirow{3}{*}{3} \\
\hline & & $48-53 \mathrm{~min}$ & $33 / 67-59 / 41$ & \\
\hline & & $53-65 \mathrm{~min}$ & $59 / 41$ & \\
\hline \multirow{3}{*}{ Trap 4} & \multirow{3}{*}{$\begin{array}{c}\text { SPE4 } \\
\text { Column } 2.4\end{array}$} & $0-48 \min$ & $14 / 86-37 / 63$ & \multirow{3}{*}{3} \\
\hline & & $48-53 \mathrm{~min}$ & $37 / 63-63 / 37$ & \\
\hline & & $53-65 \mathrm{~min}$ & $63 / 37$ & \\
\hline \multirow{3}{*}{ Trap 5} & \multirow{3}{*}{$\begin{array}{c}\text { SPE5 } \\
\text { Column } 2.4\end{array}$} & $0-48 \mathrm{~min}$ & $19 / 81-43 / 57$ & \multirow{3}{*}{3} \\
\hline & & $48-53 \mathrm{~min}$ & $43 / 57-67 / 33$ & \\
\hline & & $53-65 \mathrm{~min}$ & $67 / 33$ & \\
\hline \multirow{3}{*}{ Trap 6} & \multirow{3}{*}{$\begin{array}{c}\text { SPE6 } \\
\text { Column } 2.5^{\mathrm{b}}\end{array}$} & $0-48 \min$ & $25 / 75-48 / 52$ & \multirow{3}{*}{3} \\
\hline & & $48-53 \mathrm{~min}$ & $48 / 52-71 / 29$ & \\
\hline & & $53-65 \mathrm{~min}$ & $71 / 29$ & \\
\hline \multirow{3}{*}{ Trap 7} & \multirow{3}{*}{$\begin{array}{c}\text { SPE13 } \\
\text { Column } 2.5\end{array}$} & $0-48 \min$ & $32 / 68-58 / 42$ & \multirow{3}{*}{3} \\
\hline & & $48-53 \mathrm{~min}$ & $58 / 42-78 / 22$ & \\
\hline & & $53-65 \mathrm{~min}$ & $78 / 22$ & \\
\hline \multirow{3}{*}{ Trap 8} & \multirow{3}{*}{$\begin{array}{c}\text { SPE14 } \\
\text { Column } 2.5\end{array}$} & $0-48 \mathrm{~min}$ & $38 / 62-66 / 34$ & \multirow{3}{*}{3} \\
\hline & & $48-53 \mathrm{~min}$ & $66 / 34-85 / 15$ & \\
\hline & & $53-65 \mathrm{~min}$ & $85 / 15$ & \\
\hline \multirow{3}{*}{ Trap 9} & \multirow{3}{*}{$\begin{array}{c}\text { SPE15 } \\
\text { Column } 2.5\end{array}$} & $0-48 \min$ & $45 / 55-72 / 28$ & \multirow{3}{*}{3} \\
\hline & & $48-53 \min$ & $72 / 28-92 / 8$ & \\
\hline & & $53-65 \min$ & $92 / 8$ & \\
\hline & & $0-48 \mathrm{~min}$ & 56/44-83/17 & \\
\hline Trap 10 & $\begin{array}{l}\text { SPE16 } \\
\text { Column } 25\end{array}$ & $48-53 \mathrm{~min}$ & $83 / 17-100 / 0$ & 3 \\
\hline & & $53-65 \mathrm{~min}$ & $100 / 0$ & \\
\hline & & $0-48 \min$ & $60 / 40-87 / 13$ & \\
\hline Trap 11 & SPE17 & $48-53 \min$ & $87 / 13-100 / 0$ & 3 \\
\hline & & $53-65 \mathrm{~min}$ & $100 / 0$ & \\
\hline & & $0-48 \mathrm{~min}$ & $67 / 33-95 / 5$ & \\
\hline Trap 12 & $\begin{array}{l}\text { SPE18 } \\
\text { Column } 26\end{array}$ & $48-53 \mathrm{~min}$ & $95 / 5-100 / 0$ & 3 \\
\hline & & $53-65 \mathrm{~min}$ & $100 / 0$ & \\
\hline
\end{tabular}

A: Column 2.4: YMC-pack ODS-AQ HG, 250×10.0 mm, $10 \mu \mathrm{m}$

B: Column 2.5: Phenomenex Luna C18, 250×10.0 mm, $10 \mu \mathrm{m}$

C: Column 2.6: Phenomenex Luna C8, 250×10.0 mm, $10 \mu \mathrm{m}$

Inhibition rate $(\%)$

$=\left[1-\left(\mathrm{Abs}_{\text {sample }}-\mathrm{Abs}_{\text {reference }}\right) / \mathrm{Abs}_{\text {control }}\right] \times 100$,

$\mathrm{Abs}_{\text {sample: }}$ : Absorbance of the sample

Abs blank: Absorbance of the sample reference

$\mathrm{Abs}_{\text {control }}$ : Absorbance of the control

\section{산가수분해}

본 연구에서 수행된 가수분해는 $\mathrm{CP} 15 \mathrm{mg} / \mathrm{mL}(\mathrm{MeOH})$ :water: $\mathrm{MeOH}: 3 \mathrm{M} \quad \mathrm{HCl}=2 \mathrm{~mL}: 3 \mathrm{~mL}: 5 \mathrm{~mL}: 0 \mathrm{~mL}$ (control) $/ 2 \mathrm{~mL}: 2.7 \mathrm{~mL}$ :5 mL:0.3 mL (Final HCl conc. 0.1M)/2 mL:1.5 mL:5 mL: $1.5 \mathrm{~mL}$ (Final $\mathrm{HCl}$ conc. $0.5 \mathrm{M}$ ) $/ 2 \mathrm{~mL}: 0 \mathrm{~mL}: 5 \mathrm{~mL}: 3 \mathrm{~mL}$ (Final $\mathrm{HCl}$ conc. $1 \mathrm{M}$ )로 각각 혼합 후, $60{ }^{\circ} \mathrm{C}$ 에서 1,3 시간 동안 반응시켰 


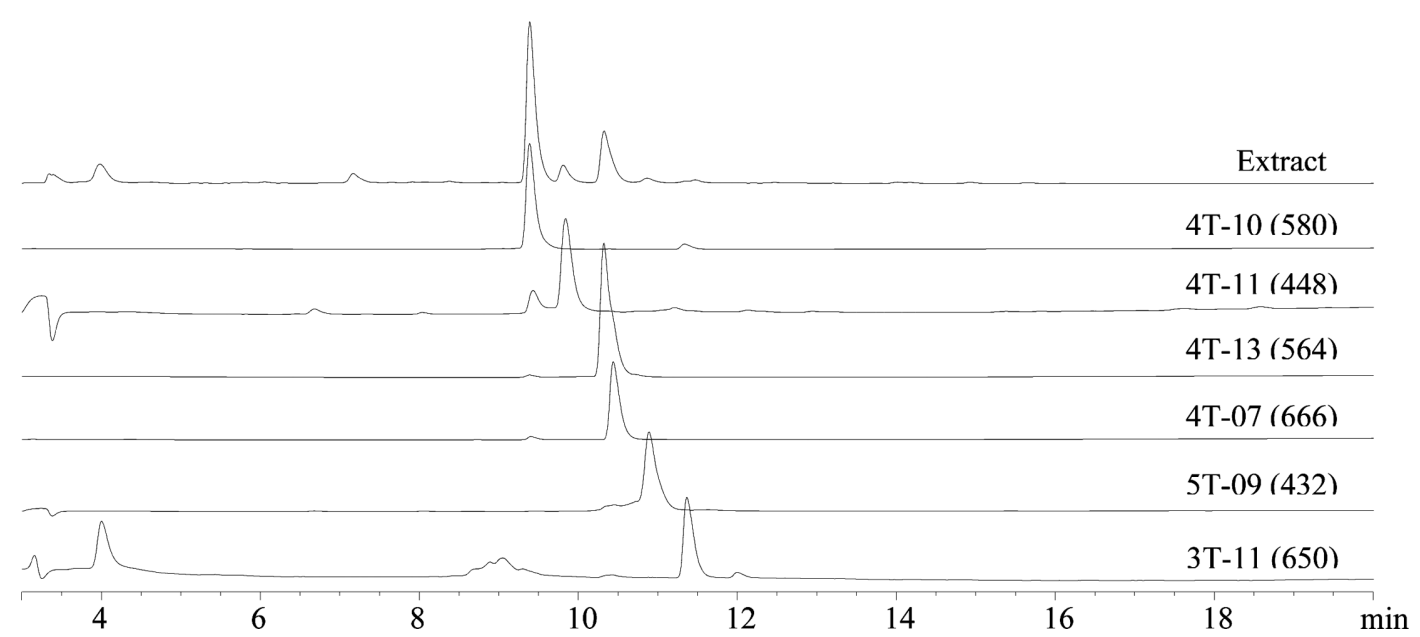

Fig. 1 HPLC chromatogram of CP1 sepbox subfractions The molecular weight of the main component is indicated in parentheses

다. 이후, 반응액은 $1 \mathrm{M} \mathrm{NaOH}$ 로 중화하고 부탄올 분획 후 농 축하여 시료화하였다.

\section{결 과}

Sepbox chromatography 소분흭 분석 및 $\alpha$-glucosidase inhibition activity

CP1 $250 \mathrm{mg}$ 을 Sepbox chromatography를 이용하여 20시간 이 내에 288개의 소분획으로 분리하였으며, 일부 소분획물의 HPLC 크로마토그램은 Fig. 1에 나타내었다. Fig. 1에서 보이는 대로, Sepbox system을 통해 $\mathrm{CP} 1$ 을 1-3개의 화합물을 포함한 소분획 으로 분리할 수 있었으며, 분리에 소모된 시간은 20 시간 이내 였다. 소분획 중 단일물질 수준으로 분리가 된 것으로 예상되 는 시료를 $\mathrm{LC}-\mathrm{MS}$ 을 통해 분석한 결과, UV흡수스펙트럼과 분 자량 정보를 바탕으로 4T-10은 luteolin 7-O-(2"-O-apiosyl) glucoside (L7AG), 4T-11은 luteolin 7-O-glucoside (L7G), 4T13은 apigenin 7-O-(2"-O-apiosyl)glucoside (A7AG), 4T-07은 luteolin 7-O-(2"-O-apiosyl-O-6"-malonyl)glucoside (L7AMG), 5T-09는 apigenin 7-O-glucoside (A7G), 3T-11은 apigenin 7$O$-(2"-O-apiosyl-O-6"-malonyl)glucoside (A7AMG)으로 추정되었 다(Table 3 ).

이후 각 소분획물의 $\alpha$-glucosidase inhibitory (AGI) activity 를 측정하기 위해 농축 후, 각각을 $\mathrm{DMSO}$ 에 용해시켰다. $\mathrm{AGI}$ 활성 결과, 3T-13 (23.13 $\pm 7.61 \%), 4 \mathrm{~T}-11$ (44.20 $\pm 5.55 \%), 4 \mathrm{~T}-18$ (25.26 $\pm 5.76 \%), \quad 4 \mathrm{~T}-19 \quad(24.17 \pm 7.01 \%), \quad 5 \mathrm{~T}-13 \quad(37.94 \pm 9.16 \%)$, 5T-14 (61.25 $\pm 2.16 \%), 8 \mathrm{~T}-2 \quad(67.03 \pm 5.90 \%), 9 \mathrm{~T}-2 \quad(31.99 \pm 10.26 \%)$ 로 총 8 개의 소분획물이 AGI activity를 가지는 것으로 나타났 다(Fig. 2). 상기 소분획의 활성물질을 조사하기 위해 LC-MS 분석을 수행하였다.

\section{활성 분흭물의 LC-MS 분석}

활성을 나타낸 소분획을 $\mathrm{LC}-\mathrm{MS}$ 를 통해 분석하였으며 그 결과, 3T-13과 4T-11에서 분자량 $448 \mathrm{Da}$ 의 luteolin 7-O-glucoside (L7G)가 확인되었고 AGI 활성을 나타낸 추가분획 4T-18,19, $5 \mathrm{~T}-13,14$ 에서는 $283 \mathrm{Da}$ 과 $313 \mathrm{Da}$ 의 분자량, $8 \mathrm{~T}-02,9 \mathrm{~T}-02$ 에서

Table 3 UHPLC-HRMS analysis results of luteolin and apigenin glycosides contained in CP1

\begin{tabular}{|c|c|c|c|c|c|}
\hline $\begin{array}{l}\text { Retention time } \\
{[\mathrm{min}]}\end{array}$ & Peak Mass & $\begin{array}{c}\text { Molecular } \\
\text { Formula }\end{array}$ & $\begin{array}{l}\text { Delta } \\
\text { [ppm] }\end{array}$ & $\begin{array}{c}\text { Theoretical } \\
\text { mass }\end{array}$ & Corresponding molecule \\
\hline $\begin{array}{c}3.66 \\
(11.84)^{*}\end{array}$ & 581.1519 & $\mathrm{C}_{26} \mathrm{H}_{29} \mathrm{O}_{15}$ & 3.03 & 581.1501 & luteolin 7-O-(2"-O-apiosyl)glucoside \\
\hline $\begin{array}{c}3.75 \\
(12.27)^{*}\end{array}$ & 449.1097 & $\mathrm{C}_{21} \mathrm{H}_{21} \mathrm{O}_{11}$ & 4.17 & 449.1078 & luteolin 7-O-glucoside \\
\hline $\begin{array}{c}3.99 \\
(12.75)^{*}\end{array}$ & 565.1570 & $\mathrm{C}_{26} \mathrm{H}_{29} \mathrm{O}_{14}$ & 3.29 & 565.1552 & apigenin 7-O-(2"-O-apiosyl)glucoside \\
\hline $\begin{array}{c}3.40 \\
(12.80)\end{array}$ & 667.1517 & $\mathrm{C}_{29} \mathrm{H}_{31} \mathrm{O}_{18}$ & 1.77 & 667.1505 & luteolin 7-O-(2"-O-apiosyl-O-6"-malonyl)glucoside \\
\hline $\begin{array}{c}4.13 \\
(13.30)^{*}\end{array}$ & 433.1145 & $\mathrm{C}_{21} \mathrm{H}_{21} \mathrm{O}_{10}$ & 3.57 & 433.1129 & apigenin 7-O-glucoside \\
\hline $\begin{array}{c}4.32 \\
(13.83)^{*}\end{array}$ & 651.1580 & $\mathrm{C}_{29} \mathrm{H}_{31} \mathrm{O}_{17}$ & 3.75 & 651.1556 & apigenin 7-O-(2"-O-apiosyl-O-6"-malonyl)glucoside \\
\hline
\end{tabular}

*HPLC retention time 


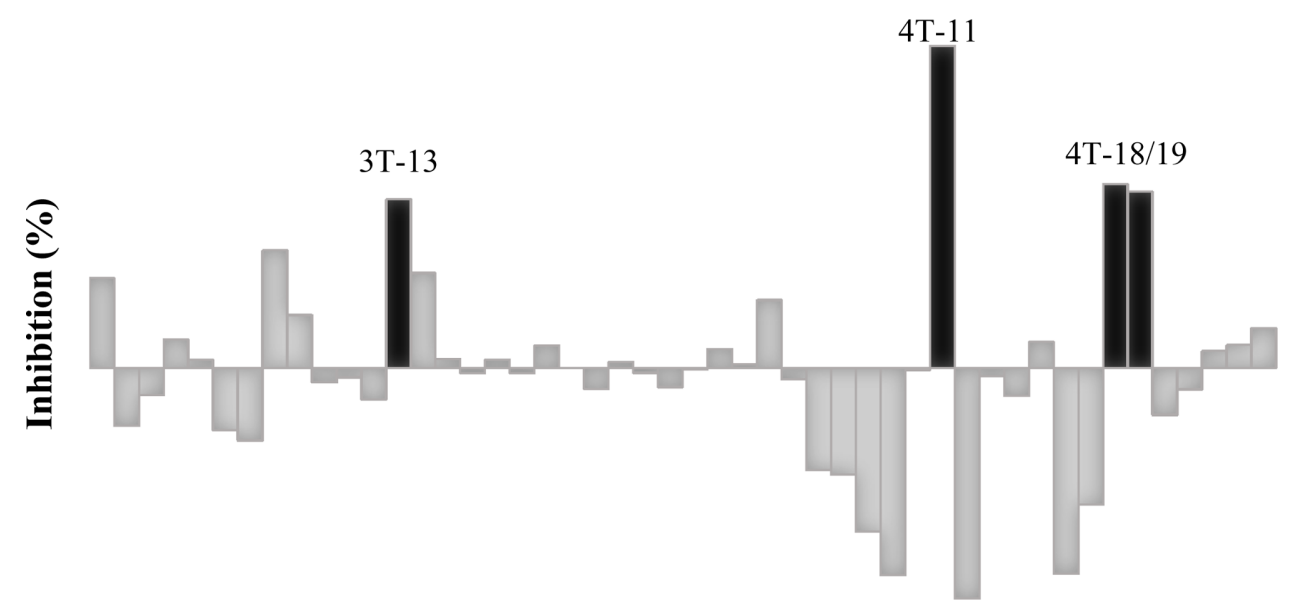

\begin{tabular}{cccc}
\hline \hline Sample & Inhibition (\%) & Sample & Inhibition (\%) \\
\hline Control & - & Acarbose & $55.40 \pm 7.61$ \\
3T-13 & $23.13 \pm 7.61$ & $4 \mathrm{~T}-18$ & $25.26 \pm 5.76$ \\
4T-11 & $44.20 \pm 5.55$ & $4 \mathrm{~T}-19$ & $24.17 \pm 7.01$ \\
\hline
\end{tabular}

Fig. $2 \alpha$-glucosidase inhibition activity of CP1 sepbox subfractions (1T $\sim 4$ fraction)

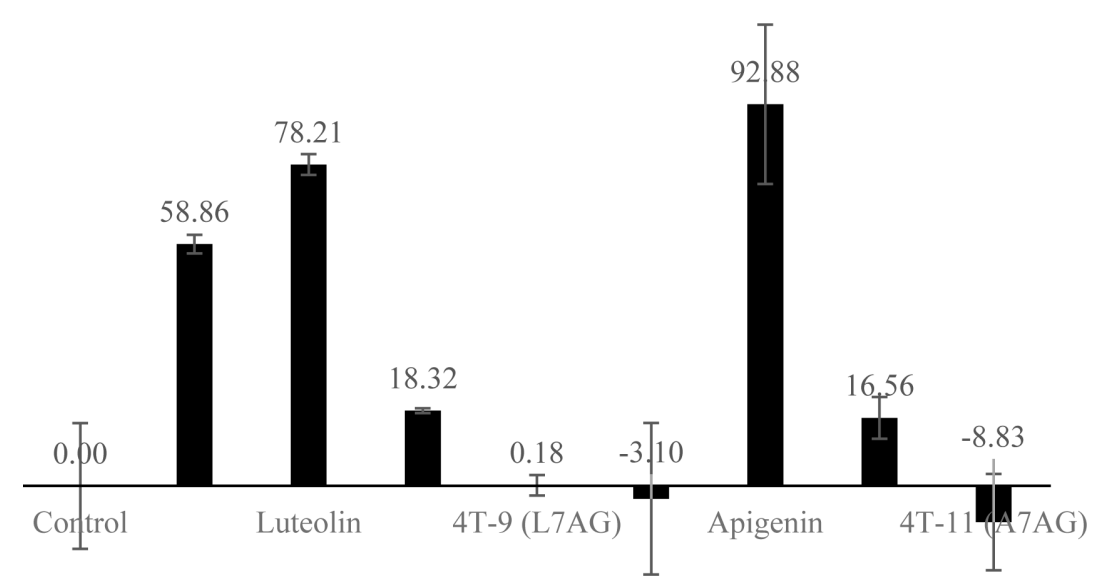

\begin{tabular}{cc}
\hline \hline Sample $(20 \mu \mathrm{g} / \mathrm{mL})$ & AGI activity (\%) \\
\hline Control & 0 \\
Acarbose $(500 \mu \mathrm{M})$ & $58.85 \pm 2.26$ \\
Luteolin & $78.21 \pm 2.55$ \\
L7G & $18.32 \pm 0.58$ \\
4T-9 (L7AG) & $0.18 \pm 2.47$ \\
3T-5 (L7AMG) & $-3.10 \pm 18.44$ \\
Apigenin & $92.87 \pm 19.37$ \\
A7G & $16.55 \pm 5.06$ \\
4T-11 (A7AG) & $-8.82 \pm 11.71$ \\
\hline
\end{tabular}

Fig. 3 AGI activity comparison result of luteolin, apigenin, and its glycosides

$660 / 1085 / 1101 / 923 \mathrm{Da}$ 의 분자량이 검출되었다. 이를 통해 $\mathrm{CP} 1$ 에서 AGI 활성을 나타내는 7개 이상의 활성물질이 예상되었고, 이들 중 하나는 $\mathrm{L} 7 \mathrm{G}$ 임을 알 수 있었다. 그 외 화합물은 미량 성분으로 구조 규명을 위하여 현재 추가 연구 중이다. $\mathrm{L} 7 \mathrm{G}$ 는 luteolin의 배당체로 $\mathrm{A} 7 \mathrm{G}$ 와 함께 $\mathrm{AGI}$ 활성을 나타낸다고 보고 되어 있다[23,24]. 그러나 본 연구의 $\mathrm{A} 7 \mathrm{G}$ 를 포함한 소분획에서 는 활성이 나타나지 않았는데 이는 $\mathrm{CP} 1$ 에서 $\mathrm{L} 7 \mathrm{G}$ 의 함유량에 비해 $\mathrm{A} 7 \mathrm{G}$ 의 함유량이 9배 가량 낮기 때문으로 추정된다(Fig. 5). 


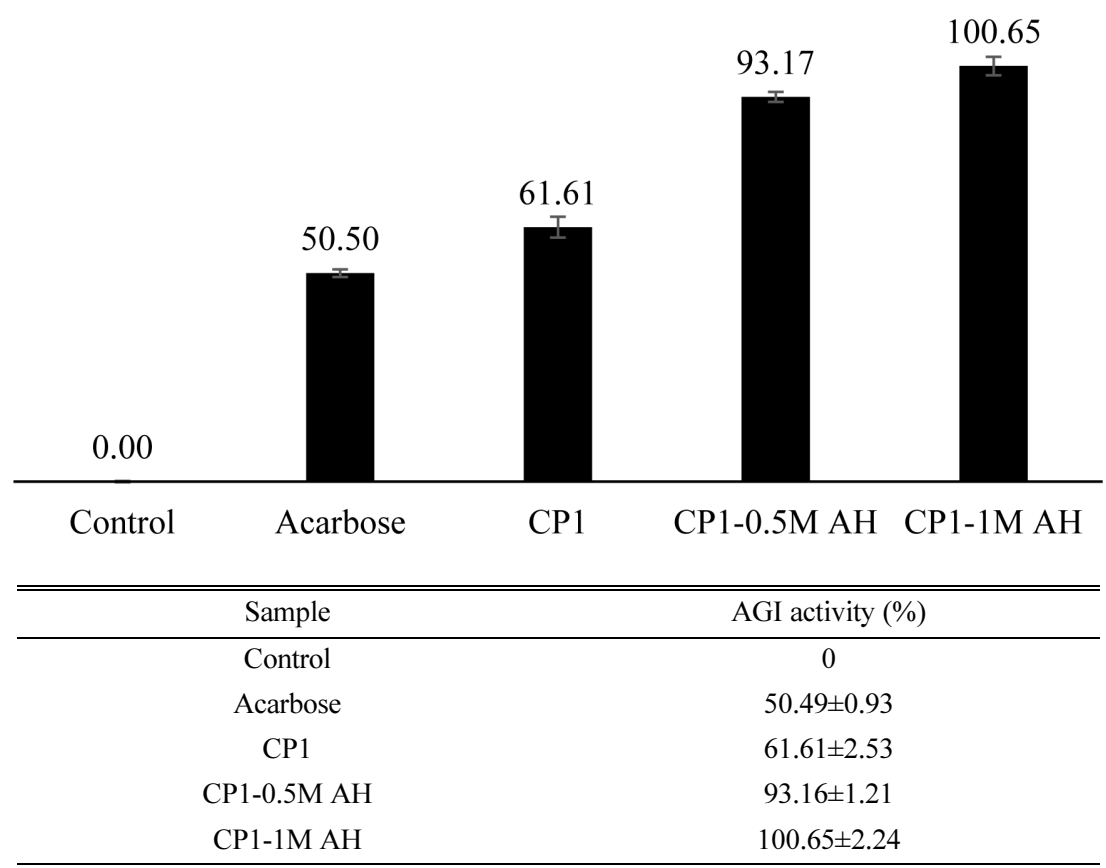

Fig. 4 Results of changes in AGI activity following deglycosylation of glycosides

또한, 각기 다른 소분획에서 같은 화합물이 검출되는 것은 Sepbox system의 1차 분리 중 물질이 완벽하게 나누어져 SPE 에 trapping이 될 수 없기 때문에 같은 화합물이 다른 trap에서 적절한 용매 조건일 때 용출되어 나와 생긴 결과로 판단된다.

추가적으로, 고추잎 추출물에 포함되어 있는 luteolin과 apigenin의 배당체인 $\mathrm{L} 7 \mathrm{G}, \mathrm{L} 7 \mathrm{AG}, \mathrm{L} 7 \mathrm{AMG}, \mathrm{A} 7 \mathrm{G}, \mathrm{A} 7 \mathrm{AG}$ $\mathrm{A} 7 \mathrm{AMG}$ 이 포함된 각각의 소분획별 $\mathrm{AGI}$ 활성을 비교한 결과, 당의 개수가 증가함에 따라 $\mathrm{AGI}$ 활성이 감소하는 경향을 확인 할 수 있었다. 이와 같은 현상의 상관관계를 명확히 하기 위해 추가적인 연구를 수행하였다.

Luteolin과 apigenin 배당체들의 $\alpha$-glucosidase inhibition activity Luteolin, apigenin, L7G, L7AG L7AMG, A7G A7AG, A7AMG 를 각각 $20 \mu \mathrm{g} / \mathrm{mL}$ 의 농도로 하여 $\mathrm{AGI}$ activity를 측정한 결과, luteolin $\quad(78.21 \pm 2.55 \%)>\mathrm{L} 7 \mathrm{G} \quad(18.32 \pm 0.58 \%)>\mathrm{L} 7 \mathrm{AG} \quad(0.18 \pm$ $2.47 \%)>\mathrm{L} 7 \mathrm{AMG}(-3.10 \pm 18.44)$ 순으로 활성이 감소하였으며, apigenin (92.87 \pm 19.37$)>$ A7G (16.55 \pm 5.06$)>$ A7AG (-8.82 11.71)으로 apigenin 또한 동일한 결과를 보였다(Fig. 3).

위 결과를 바탕으로 본 연구자들은 $\mathrm{CP} 1$ 에 포함된 luteolin과 apigenin의 배당체를 deglycosylation 시킬 경우, 추출물의 AGI 활성이 증가할 것임을 가정하였고, 이를 증명하기위해 $\mathrm{CP} 1$ 에 보유중인 해양미생물을 이용하여 생물전환을 실시하였으나 당 의 가수분해 산물을 확인하지는 못하였고(data not shown) 추가 적으로 염산 $(\mathrm{HCl})$ 을 처리하여 산가수분해를 진행하였다. 탈당화 (deglycosylation)에 따른 활성 변화를 조사한 결과, CP1 0.5 $\mathrm{mg} / \mathrm{mL}(61.61 \pm 2.53 \%)$ 에 비해 $0.5 \mathrm{M} \mathrm{HCl}$ 을 통해 탈당화 시료 $(\mathrm{CP} 1-0.5 \mathrm{M} \mathrm{AH})$ 는 $93.16 \pm 1.21 \%$ 로 $\mathrm{AGI}$ 활성이 약 $32 \%$ 증가 하였으며, $1 \mathrm{M} \mathrm{HCl}$ 을 통해 탈당화 시료 $(\mathrm{CP} 1-1 \mathrm{M} \mathrm{AG})$ 는 $100.65 \pm$ $2.24 \%$ 로 약 $39 \%$ 증가하였다(Fig. 4).

또한, 가수분해 반응시료를 HPLC를 통해 분석한 결과, CP1
내에 존재하던 $\mathrm{L} 7 \mathrm{AG}$ 및 $\mathrm{A} 7 \mathrm{AG}$ 가 $\mathrm{L} 7 \mathrm{G}$ 와 $\mathrm{A} 7 \mathrm{G}$ 로 탈당화된 것 을 확인하였다(Fig. 5). 위의 결과를 통해 탈당화에 의해 $\alpha$ glucosidase inhibition 활성이 증가한다는 것을 확인하였다.

고 찰

본 연구에서 활용한 Sepbox 시스템은 천연물을 거의 순수한 화 합물이나 몇 가지 물질의 혼합물로 신속하게 분리하는 시스템 이며, 4 개의 HPLC 컬럼, 12 개의 SPE용 컬럼, 광 산란 검출기 및 $\mathrm{UV}$ 검출기가 결합되어 있다. 이러한 $\mathrm{HPLC} / \mathrm{SPE} / \mathrm{HPLC}$ coupling system을 통해 20시간 이내에 288개의 CP1 소분획물 을 획득할 수 있었으며, UHPLC-HRMS를 통해 luteolin과 apigenin의 배당체인 $\mathrm{L} 7 \mathrm{G}, \mathrm{L} 7 \mathrm{AG}, \mathrm{L} 7 \mathrm{AMG}$ 와 A7G, A7AG, $\mathrm{A} 7 \mathrm{AMG}$ 등을 확인하였다. $\mathrm{CP} 1$ 은 지표물질이 뚜렷하여 상대적 으로 함유량이 낮은 물질을 분석하기가 어려우나, Sepbox system을 이용하여 미량물질들을 빠르고 효과적으로 분리 및 분 석할 수 있었다. 이와 같은 Sepbox system은 천연물 분리 연구 에 적용되어 높은 활용성을 나타낼 것이라 사료된다.

Sepbox을 통해 얻은 소분획물들의 AGI activity 측정을 통해 활성을 확인하였다. 이들 소분획 중, 하나는 448 의 분자량을 가 지는 $\mathrm{L} 7 \mathrm{G}$ 을 주로 함유한 것으로 확인되었다. AGI 활성을 나 타낸 $\mathrm{L} 7 \mathrm{G}$ 는 이미 보고된 연구결과[23]와 동일하며 Sepbox를 통해 물질이 효과적으로 분리되었음을 시사한다. 더 나아가, $\mathrm{L} 7 \mathrm{G}$ 와 마찬가지로 apigenin의 배당체인 $\mathrm{A} 7 \mathrm{G}$ 도 $\mathrm{AGI}$ 활성이 보 고되어 있는데[24], 본 연구의 $\mathrm{A} 7 \mathrm{G}$ 를 포함한 소분획에서는 활 성이 나타나지 않았다. 이는 $\mathrm{CP} 1$ 에서 $\mathrm{L} 7 \mathrm{G}$ 의 함유량에 비해 $\mathrm{A} 7 \mathrm{G}$ 의 함유량이 $1 / 9$ 정도로 낮기 때문으로 추정된다. 나머지 활성분획의 함유성분 규명을 위한 추가적인 연구를 수행 중이다. 또한, 우리는 Sepbox 소분획별 AGI 활성을 비교하던 중, 


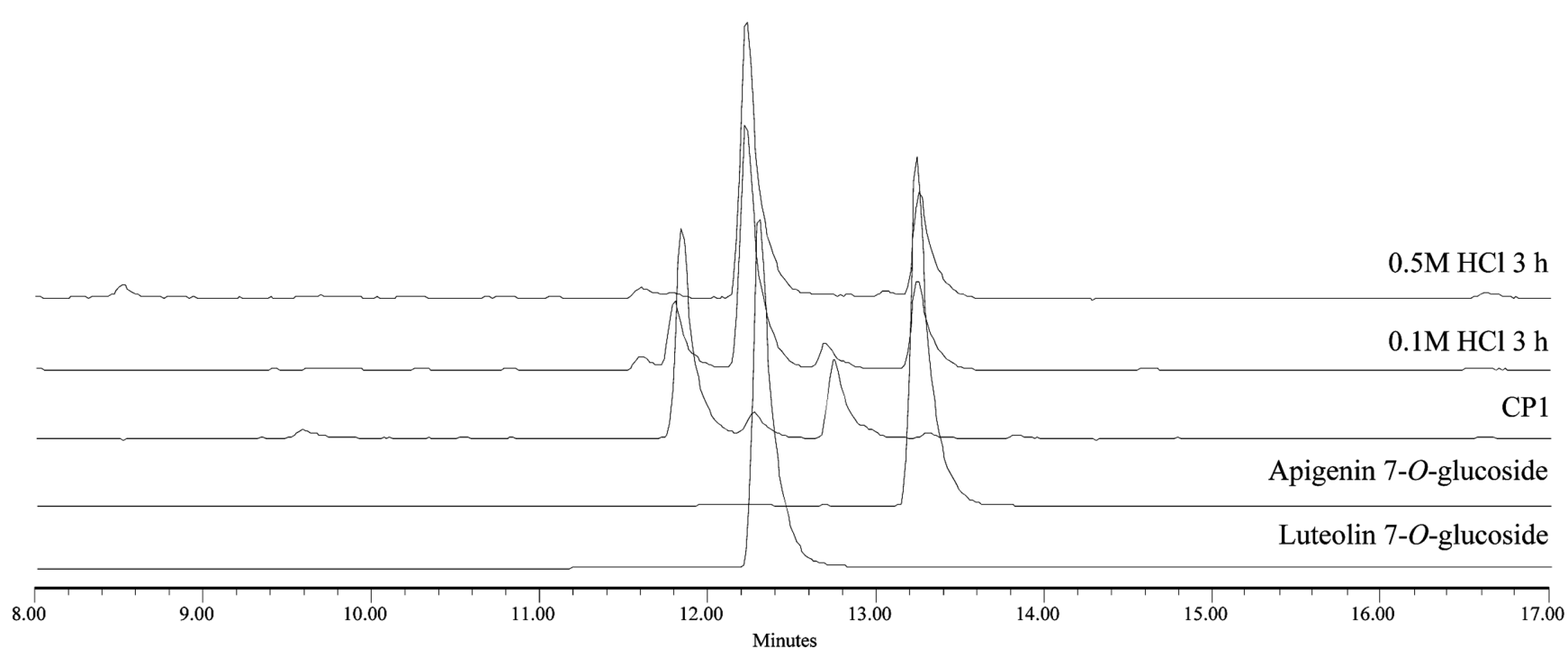

\begin{tabular}{clccc}
\hline \hline \multirow{2}{*}{ RT } & \multicolumn{1}{c}{ Corresponding molecule } & \multicolumn{2}{c}{ Area \% } \\
\cline { 3 - 5 } & & Extract & $0.1 \mathrm{M}$ Acid hydrolysis & $0.5 \mathrm{M}$ Acid hydrolysis \\
\hline 11.84 & luteolin 7-O-(2"-O-apiosyl)glucoside & 62.00 & 15.66 & 1.22 \\
12.27 & luteolin 7-O-glucoside & 9.43 & 56.16 & 70.19 \\
12.75 & apigenin 7- $O$-(2"-O-apiosyl)glucoside & 25.71 & 7.21 & 1.39 \\
13.3 & apigenin 7- $O$-glucoside & 1.77 & 20.98 & 27.20 \\
13.83 & apigenin 7-O-(2"-O-apiosyl-O-6"-malonyl)glucoside & 1.09 & ND & ND \\
\hline
\end{tabular}

Fig. 5 HPLC chromatogram analysis result after acid hydrolysis of CP1

luteolin과 apigenin 배당체의 탈당화 가수분해반응에 따른 AGI 활성 증가를 발견하였으며, 이들의 상관관계를 증명하기 위해 luteolin 및 apigenin과 이들의 배당체들의 AGI활성을 비교하였 다. 그 결과, 탈당화에 의해 $\mathrm{AGI}$ 활성이 증가함을 발견하였다. 또한, 산가수분해에 의한 배당체의 함량을 낮춘 $\mathrm{CP} 1$ 산물의 $\mathrm{AGI}$ 활성도 동일한 패턴으로 증가하였으며, 이를 통해 탈당화 에 의해 AGI 활성이 증가함을 확인하였다. 비록 luteolin과 apigenin의 AGI 활성이 이미 알려져 있으나 고추잎에는 대부분 배당체로 분포하고 있기 때문에 가수분해를 통하여 활성을 증 진시킬 수 있을 것으로 생각하며 그 외 식물에 다양하게 존재 하는 폴리페놀 배당체를 가수분해시에 기능성 향상을 기대할 수 있을 것으로 예상한다.

이와 같은 현상은 탈당화반응에 의한 분자 크기와 극성의 감 소, 그리고 평면 구조화 등이 원인일 수 있으며, 이로 인해 화 합물과 $\alpha$-glucosidase 사이의 결합 상호작용이 증가[25]하여 야 기된 결과로 판단된다.

본 연구결과는 Sepbox 시스템이 식물추출물에서 활성 성분 을 신속하게 분리하고 식별할 수 있으며, 새로운 활성 물질을 찾는데 효과적인 기술임을 시사한다.

\section{초 록}

식물 유래 화합물은 다양한 생리활성과 구조 다양성으로 많은
연구자에게 관심을 받고 있으나 화합물 분리는 많은 시간 소요, 과량의 유기용매 소모와 분리과정 중의 활성성분의 유실 등의 어려움을 겪게 된다. 이러한 점을 극복하기 위하여 HPLC/SPE/ $\mathrm{HPLC}$ 를 결합한 Sepbox 분리시스템을 이용하여 고추잎 추출물 에서 288개 분획물을 획득하였고 이 중에서 alpha-glucosidase 저해효능을 가지는 화합물인 luteolin 7-O-glucoside를 효과적으 로 확인할 수 있었다. 또한 고추잎에 풍부한 플라보노이드 다 당체를 가수분해함에 따라 해당 활성이 증가함을 검증하였다. 그러므로 본 연구결과는 Sepbox 시스템이 생리활성 평가와 결 합할 경우 식물 내 유용물질 탐색에 효과적임을 보여주었다.

Keywords $\alpha$-glucosidase 저해활성 · Capsicum annuum L. · $\mathrm{HPLC} / \mathrm{SPE} / \mathrm{HPLC}$ 자동화시스템

감사의 글 이 논문은 2020 년 해양수산부 재원으로 해양수산과학기술진흥 원의 지원을 받아 수행된 연구임(해외 해양생물자원 개발 및 활용기반 구축, 20170488).

\section{References}

1. Aruoma O, Spencer J, Rossi R, Aeschbach R, Khan A, Mahmood N, Munoz A, Murcia A, Butler J, Halliwell B (1996) An evaluation of the antioxidant and antiviral action of extracts of rosemary and Provencal herbs. Food Chem Toxicol 34: 449-456

2. Barnes H, Feldman J, White W (1950) Isochlorogenic Acid. Isolation 
from Coffee and Structure Studies1. J AM Chem Soc 72: 4178-4182

3. Newman DJ, Cragg GM (2012) Natural products as sources of new drugs over the 30 years from 1981 to 2010 . J Nat Prod 75: 311-335

4. Fabricant DS, Farnsworth NR (2001) The value of plants used in traditional medicine for drug discovery. Environ Health Perspect 109: 69-75

5. Colegate SM, Molyneux RJ (2007) Bioactive natural products: detection, isolation, and structural determination. CRC press, Boca Raton

6. Li JWH, Vederas JC (2009) Drug discovery and natural products: end of an era or an endless frontier? Science 325: 161-165

7. Nothias LFl, Nothias-Esposito Ml, da Silva R, Wang M, Protsyuk I, Zhang Z, Sarvepalli A, Leyssen P, Touboul D, Costa J (2018) Bioactivity-based molecular networking for the discovery of drug leads in natural product bioassay-guided fractionation. J Nat Prod 81: 758-767

8. Yang Y, Gu L, Xiao Y, Liu Q, Hu H, Wang Z, Chen K (2015) Rapid identification of $\alpha$-glucosidase inhibitors from Phlomis tuberosa by sepbox chromatography and thin-layer chromatography bioautography. PLoS One 10: e0116922

9. Kwon HC, Cha JW, Park JS, Chun YS, Moodley N, Maharaj VJ, Youn SH, Chung SK, Yang HO (2011) Rapid identification of bioactive compounds reducing the production of amyloid $\beta$-peptide $(A \beta)$ from South African plants using an automated HPLC/SPE/HPLC coupling system. Biomol Ther (Seoul) 19: 90-96

10. Bhandari M, Anil B, Bhandari A (2011) Sepbox technique in natural products. J Young Pharm 3: 226-231

11. Davies B, Matthews S, Kirk J (1970) The nature and biosynthesis of the carotenoids of different colour varieties of Capsicum annuum. Phytochemistry 9: 797-805

12. Park CR (1975) A study on the influence of drying methods upon the chemical changes in red pepper. J Nutr Health 8: 27-32

13. Kim SA, Kim KS, Park JB (2006) Changes of various chemical components by the difference of the degree of ripening and harvesting factors in two single-harvested peppers (Capsicum annuum, L.). Korean J Food Sci Technol 38: 615-620

14. Lee JH, Kim BH, Yoon YC, Kim JG, Park YE, Park HS, Kwun IS, Kwon GS, Lee JB (2019) Effects Against Obesity and Diabetes of Red Pepper (Capsicum annuum L.) Fermented with Lactic Acid Bacteria.
Life Sci 29: 354-361

15. Hallmann E, Rembiałkowska E (2012) Characterisation of antioxidant compounds in sweet bell pepper (Capsicum annuum L.) under organic and conventional growing systems. J Sci Food Agric 92: 2409-2415

16. Sun $\mathrm{T}, \mathrm{Xu} \mathrm{Z}$, Wu CT, Janes M, Prinyawiwatkul W, No H (2007) Antioxidant activities of different colored sweet bell peppers (Capsicum annuum L.). J Food Sci 72: S98-S102

17. Othman ZAA, Ahmed YBH, Habila MA, Ghafar AA (2011) Determination of capsaicin and dihydrocapsaicin in Capsicum fruit samples using high performance liquid chromatography. Molecules 16: 8919-8929

18. Thuphairo K, Sornchan P, Suttisansanee U (2019) Bioactive Compounds, Antioxidant Activity and Inhibition of Key Enzymes Relevant to Alzheimer's Disease from Sweet Pepper (Capsicum annuum) Extracts. Prev Nutr Food Sci 24: 327

19. Stratton IM, Adler AI, Neil HAW, Matthews DR, Manley SE, Cull CA, Hadden D, Turner RC, Holman RR (2000) Association of glycaemia with macrovascular and microvascular complications of type 2 diabetes (UKPDS 35): prospective observational study. Br Med J 321: 405-412

20. King H, Aubert RE, Herman WH (1998) Global burden of diabetes, 1995-2025: prevalence, numerical estimates, and projections. Diabetes care 21: 1414-1431

21. Cho MC, Park DB, Yang EY, Pae DH, Won SR, Yu WK, Rhee HI (2007) Selection and Horticultural Characteristics Evalution of High $\alpha$ Glucosidase Inhibitor in Pepper. Protected Hort Plant Fac 16: 233-239

22. Misbah H, AA Aziz, N Aminudin (2013) Antidiabetic and antioxidant properties of Ficus deltoidea fruit extracts and fractions. BMC Complement Altern Med 13(1): 118

23. Yan J, Zhang G, Pan J, Wang Y (2014) $\alpha$-Glucosidase inhibition by luteolin: Kinetics, interaction and molecular docking. Int $\mathrm{J}$ Biol Macromol 64: 213-223

24. Zeng L, Zhang G, Lin S, Gong D (2016) Inhibitory mechanism of apigenin on $\alpha$-glucosidase and synergy analysis of flavonoids. J Agric Food Chem 64 (37): 6939-6949

25. Xiao J (2017) Dietary flavonoid aglycones and their glycosides: Which show better biological significance? Crit Rev Food Sci Nutr 57(9): 1874-1905 